\title{
Benefits of Early Tracheotomy: A Meta-analysis Based on 6 Observational Studies
}

\author{
Liang Shan MD, Panpan Hao MD, Feng Xu MD, and Yu-Guo Chen MD
}

\begin{abstract}
BACKGROUND: Whether early tracheotomy can improve the clinical outcomes of critically ill patients remains controversial. The current study aimed to discuss the potential benefits of early tracheotomy compared to late tracheotomy with meta-analysis of observational studies. METHODS: An electronic search (up to February 28, 2013) was conducted by a uniform requirement, and then clinical data satisfying the predefined inclusion criteria were extracted. RESULTS: Data from a total of 2,037 subjects were included from 6 observational retrospective studies. Meta-analysis suggested that early tracheotomy was associated with significant reductions in mortality (odds ratio 0.77, 95\% CI 0.62-0.96), duration of mechanical ventilation (mean difference $-\mathbf{1 0 . 0 4}, \mathbf{9 5 \%}$ CI $\mathbf{- 1 5 . 1 5}$ to $\mathbf{- 4 . 9 2}$ ), ICU stay (mean difference $\mathbf{- 8 . 8 0} \mathrm{d}, \mathbf{9 5 \%}$ CI $\mathbf{- 9 . 7 1}$ to $\mathbf{- 7 . 8 9} \mathrm{d}$ ), and hospital stay

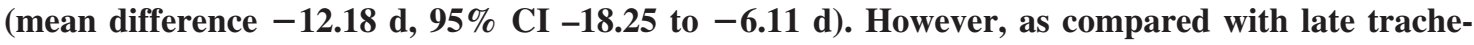
otomy, early tracheotomy did not reduce the incidence of ventilator-associated pneumonia. CONCLUSIONS: Our meta-analysis of retrospective observational studies suggests that early tracheotomy performed between days 3 and 7 after intubation had some advantages, including decreased mortality and reduced ICU stay, hospital stay, and mechanical ventilation duration in ICU patients. Key words: tracheotomy; ICU; critically ill patients; mechanical ventilation; meta-analysis. [Respir Care 2013;58(11):1856-1862. () 2013 Daedalus Enterprises]
\end{abstract}

\section{Introduction}

Tracheotomy was originally a usual procedure that was performed in only $6 \%$ of critically ill patients, for the purpose of prolonged mechanical ventilation or airway support. ${ }^{1,2}$ The development of the percutaneous dilatation technique allowed physicians to perform tracheotomies at the bedside rather than in an operating room, which dramatically increased the number performed. ${ }^{3,4}$ There are

\footnotetext{
The authors are affiliated with the Emergency Department, Qilu Hospital, Shandong University, Jinan, China. Dr Shan is also affiliated with the Neurological Intensive Care Unit, Affiliated Hospital of Medical College, Qingdao University, Jinan, China. Dr Chen is also affiliated with Key Laboratory of Cardiovascular Remodeling and Function Research, Chinese Ministry of Education and Chinese Ministry of Public Health, Qilu Hospital, Shandong University, Jinan, China.
}

The authors have disclosed no conflicts of interest.

Correspondence: Yu-Guo Chen MD, Emergency Department, Qilu Hospital, Shandong University, Jinan, China. E-mail: chen110309@yeah.net.

DOI: $10.4187 /$ respcare. 02413 several advantages associated with tracheotomy, such as efficient suctioning of secretions, easier nursing care, greater comfort, less sedation, smaller dead space, and lower airway resistance. ${ }^{5-7}$ Complications relative to tracheotomy included stomal infection and hemorrhage, tracheal stenosis, and, occasionally, death due to innominate artery rupture. ${ }^{7,8}$

See the Related Editorial on Page 1995

However, whether early tracheotomy is more advantageous than late tracheotomy or prolonged intubation remains controversial. In 1989 the National Association of Medical Directors of Respiratory Care published a recommendation based solely on expert opinion that tracheotomy should be performed in patients who still required artificial ventilation 21 days after admission. ${ }^{9}$ However, tracheotomy timing often depended on the physician's individual views, clinical conditions, and the opinions of the patient's relatives. In a retrospective study conducted by Freeman et al, which included 2,473 patients, tracheotomy was performed after an average of 9 days of ventilatory 
support. ${ }^{2}$ Meta-analyses published in recent years were mainly based on randomized controlled trials (RCTs) that did not find any major benefits from early tracheotomy, especially for mortality outcomes. ${ }^{10-12}$

Although some observational studies published in the past several decades have been designed as prospective cohort or retrospective case-control studies, these have not been included in larger analyses. Here we aimed to systematically review available observational studies and perform a meta-analysis to investigate the relationships between tracheotomy timing and clinical outcomes of critically ill patients.

\section{Methods}

\section{Search Sources and Strategy}

We performed an electronic search (up to February 28, 2013) using the following key words: [tracheotomy] AND [intensive care unit OR critically ill patients], with no restriction on subheadings. Relevant studies were identified by searching the following data sources: MEDLINE (Ovid), EMBASE, J-STAGE, the Cochrane Library (Cochrane Central Register of Controlled Trials), Global Health, International Pharmaceutical Abstracts, ISI Web of Science, the China National Knowledge Internet, and the grey literature (SIGLE) databases. The reference lists of all retrieved studies were checked for other potentially relevant citations.

\section{Selection Criteria}

Studies were included in the present meta-analysis if they met all the following criteria: they assessed critically ill patients who were admitted to ICUs; they compared early tracheotomy ( $<7$ d) with late tracheotomy ( $\geq 7 \mathrm{~d}$ ); they were written in English; and they included prospective or retrospective observational study design. We selected 7 days as a cutoff point because the median time from onset of mechanical ventilation to tracheotomy in most observational studies was between 3 and 7 days. Most of the RCTs also selected $<7$ days as the cutoff point. ${ }^{13}$

\section{Quality Assessment and Data Extraction}

Two of the authors (LS and PH) independently and blindly selected trials according to the inclusion criteria. The quality assessment was omitted. Next we extracted information from published reports using a standardized protocol and reporting form: study design, first author's family name, year of publication, number of enrolled patients, targeted population, original country, tracheotomy timing, and available end points. If there were several mortality end points, we selected those with longer follow-up

\section{QUICK LOOK}

\section{Current knowledge}

The timing of tracheotomy (early vs late) is controversial. Outcomes, cost, and the patient's post-discharge destination are important aspects of the early versus late tracheotomy controversy.

\section{What this paper contributes to our knowledge}

This meta-analysis suggests that early tracheotomy (between day 3 and 7 after intubation) decreased mortality and shortened ICU stay, hospital stay, and duration of mechanical ventilation.

results. For example, among ICU mortality, hospital mortality, 90-day mortality, and 1-year mortality, we chose 1-year mortality as the final end point event. Duration of mechanical ventilation was measured as the time from translaryngeal intubation to weaning day/night or death. ICU stay was measured as time from admission/transfer to ICU to discharge from ICU or death. Hospital stay was measured as time from admission to hospital to discharge from hospital or death. Ventilator-associated pneumonia (VAP) was defined using respective diagnosis criteria. Disagreement was resolved by discussion and arbitration by a third author (YGC) if necessary.

\section{Statistical Analysis}

Meta-analysis software (RevMan 5.0.25, Cochrane Collaboration, http://www.cc-ims.net/revman) was used for the meta-analysis. Heterogeneity between selected articles was tested with the inconsistency index $\left(\mathrm{I}^{2}\right)$ and chi-square tests. Statistically significant heterogeneity was considered present when a chi-square $P<.10$ and $\mathrm{I}^{2}>50 \%$. We applied the fixed-effects model when there was no statistically significant difference between the results, and the random-effects model was applied when there was a significant difference. Publication bias was evaluated with funnel plots and the fail-safe number $\left(\mathrm{N}_{\mathrm{fs}}\right)$. Any calculated $\mathrm{N}_{\mathrm{fs}}$ value smaller than the number of observed studies indicated a publication bias that might influence the metaanalysis results. We calculated the $\mathrm{N}_{\mathrm{fs} 0.05}$ according to the following formula:

$$
\mathrm{N}_{\mathrm{fs} 0.05}=\left(\sum \mathrm{Z} / 1.64\right)^{2}-k
$$

where $k$ is the number of reports of studies included in the meta-analysis. 
Benefits of Early Tracheotomy: A Meta-analysis

Table. Chief Characteristics of Studies Included in the Meta-analysis

\begin{tabular}{|c|c|c|c|c|c|c|}
\hline First author & Armstrong ${ }^{19}$ & Arabi $^{20}$ & Moller $^{21}$ & Flaatten $^{22}$ & Zagli $^{23}$ & Tong $^{24}$ \\
\hline Year of publication & 1998 & 2004 & 2005 & 2006 & 2010 & 2012 \\
\hline Country & United States & Saudi Arabia & United States & Norway & Italy & United States \\
\hline Study design & $\begin{array}{l}\text { Single-center } \\
\quad \text { retrospective }\end{array}$ & $\begin{array}{l}\text { Single-center } \\
\text { retrospective }\end{array}$ & $\begin{array}{l}\text { Multi-center } \\
\text { retrospective }\end{array}$ & $\begin{array}{l}\text { Single-center } \\
\text { retrospective }\end{array}$ & $\begin{array}{l}\text { Single-center } \\
\text { retrospective }\end{array}$ & $\begin{array}{l}\text { Single-center } \\
\text { retrospective }\end{array}$ \\
\hline Number of cases & 157 & 136 & 185 & 461 & 506 & 592 \\
\hline Mean age, $y$ & 39 & 31 & 52 & 53 & 55 & 68 \\
\hline Male, $\%$ & 75 & 91 & 62 & ND & 71 & 52 \\
\hline \multicolumn{7}{|l|}{ Timing of tracheotomy } \\
\hline Early & $<6 \mathrm{~d}$ & $<7 \mathrm{~d}$ & $<7 \mathrm{~d}$ & $<6 \mathrm{~d}$ & $\leq 3 \mathrm{~d}$ & $<7 \mathrm{~d}$ \\
\hline Late & $\geq 7 \mathrm{~d}$ & $>7 \mathrm{~d}$ & $>7 \mathrm{~d}$ & $>6 \mathrm{~d}$ & $>3 \mathrm{~d}$ & $>7 \mathrm{~d}$ \\
\hline Study population & $\begin{array}{l}\text { Ventilator- } \\
\text { dependent } \\
\text { trauma patients }\end{array}$ & $\begin{array}{c}\text { Trauma ICU } \\
\text { patients }\end{array}$ & $\begin{array}{l}\text { Surgical ICU } \\
\text { patients }\end{array}$ & ICU patients & $\begin{array}{l}\text { Emergency ICU } \\
\text { patients } \\
\text { requiring } \\
\text { mechanical } \\
\text { ventilation }\end{array}$ & $\begin{array}{l}\text { Non-trauma ICU } \\
\text { patients }\end{array}$ \\
\hline Available end points & $\begin{array}{l}\text { ICU stay, hospital } \\
\text { stay, mortality }\end{array}$ & $\begin{array}{l}\text { Duration of } \\
\text { ventilation, } \\
\text { ICU stay, } \\
\text { hospital } \\
\text { stay, } \\
\text { mortality }\end{array}$ & $\begin{array}{l}\text { ICU stay, hospital } \\
\text { stay, duration } \\
\text { of ventilation, } \\
\text { VAP }\end{array}$ & $\begin{array}{l}\text { Duration of } \\
\text { ventilation, ICU } \\
\text { stay, hospital } \\
\text { stay, mortality }\end{array}$ & $\begin{array}{l}\text { VAP, duration } \\
\text { of ventilation, } \\
\text { ICU stay, } \\
\text { hospital stay, } \\
\text { mortality }\end{array}$ & $\begin{array}{l}\text { Duration of } \\
\text { ventilation, } \\
\text { ICU stay, } \\
\text { hospital stay, } \\
\text { mortality, } \\
\text { VAP }\end{array}$ \\
\hline Type of tracheotomy & Open surgery & PDT & $\begin{array}{l}\text { PDT or open } \\
\text { surgery }\end{array}$ & $\begin{array}{l}\text { PDT or open } \\
\text { surgery }\end{array}$ & PDT & Open surgery \\
\hline \multicolumn{7}{|c|}{$\begin{array}{l}\mathrm{VAP}=\text { ventilator- associated pneumonia } \\
\mathrm{ND}=\text { no data available } \\
\mathrm{PDT}=\text { percutaneous dilational tracheotomy }\end{array}$} \\
\hline
\end{tabular}

\section{Results}

A total of 11 observational studies about tracheotomy timing were identified through the electronic database search, and 4 of them ${ }^{14-17}$ were excluded because the data were not available. A study conducted by Scales and colleagues was also excluded because they selected 10 days as the cutoff. ${ }^{18}$ Ultimately, 6 retrospective observational studies including 2,037 subjects were pooled together, and the data extracted. ${ }^{19-24}$ The characteristics of the subjects and therapy information are listed in the Table.

We did not observe heterogeneity with regard to mortality or VAP outcomes $\left(P=.76, \mathrm{I}^{2}=0 \%, P=.40\right.$, $\mathrm{I}^{2}=0 \%$ ), so a fixed-effect model was used to analyze these variables. However, heterogeneity was found in terms of mechanical ventilation duration and ICU and hospital stay, so random-effects models were employed for their analysis $\left(P<.001, \mathrm{I}^{2}=100 \%, P<.001, \mathrm{I}^{2}=92 \%\right.$, $\left.P<.001, \mathrm{I}^{2}=99 \%\right)$.

\section{Clinical End Point Events}

The risk of mortality, ICU stay, hospital stay, and mechanical ventilation duration differed between the early tracheotomy groups and late tracheotomy groups. Mortality events were reviewed for 5 trials. ${ }^{19,20,22-24}$ The risk of mortality in the early tracheotomy group was significantly lower than in the late tracheotomy group (26.1\% vs $29.8 \%$, respectively, relative risk $0.77,95 \% \mathrm{CI} 0.62-0.96, P=.02$, Fig. 1). The mechanical ventilation duration in 4 trials $20,21,23,24$ was shorter in the early tracheotomy group than in the late tracheotomy group (mean difference $-10.04 \mathrm{~d}, 95 \% \mathrm{CI}-15.15$ to $-4.92, P=.001$, Fig. 2). The ICU stay was included in 5 trials $^{19-21,23,24}$ and was shorter in the early tracheotomy group, compared to the late group (mean difference $-8.8 \mathrm{~d}, 95 \% \mathrm{CI}-9.71$ to $-7.89, P<.001$, Fig. 3). The hospital stay was described in 5 trials, ${ }^{19-21,23,24}$ and again it was shorter in the early tracheotomy group (mean difference $-12.18 \mathrm{~d}$, 95\% CI -18.25 to $-6.11, P<.001$, Fig. 4). There was no significant difference in VAP prevalence between the early and late tracheotomy groups in 3 trials $(11.6 \%$ vs $11.0 \%$, respectively, odds ratio $0.71,95 \%$ CI $0.48-1.04, P=.08$, Fig. 5). ${ }^{21,23,24}$

\section{Publication Bias}

We constructed a funnel plot to identify possible publication bias of the 5 trials in terms of mortality events (Fig. 6). 


\section{Benefits of Early Tracheotomy: A Meta-analysis}

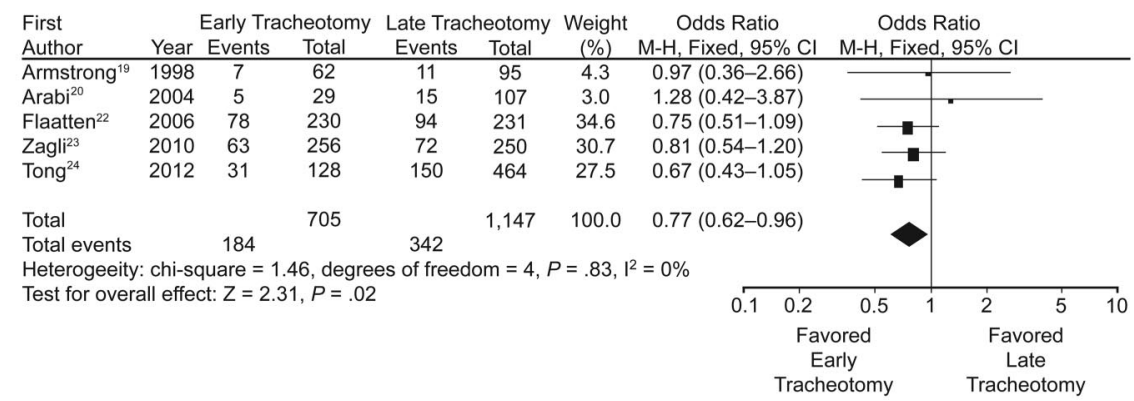

Fig. 1. Meta-analysis of 5 randomized controlled trials on the impact of early versus late tracheotomy on mortality. $\mathrm{M}-\mathrm{H}=\mathrm{Mantel}-\mathrm{Haenszel}$ test.

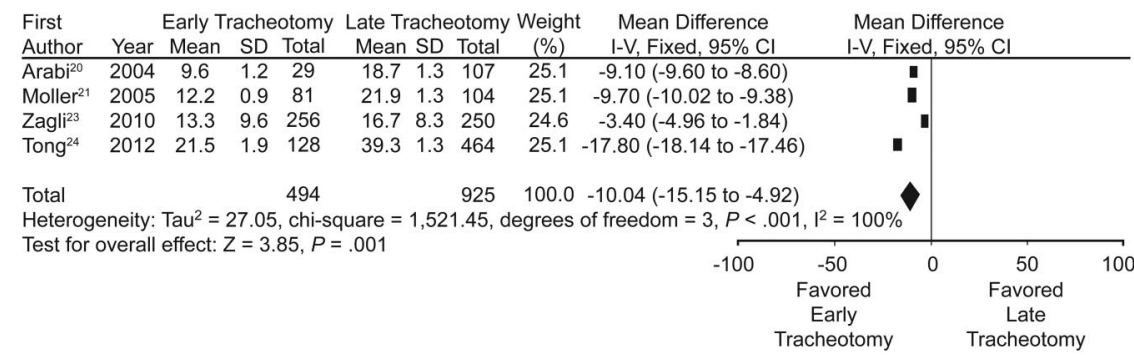

Fig. 2. Meta-analysis of 4 randomized controlled trials on the impact of early versus late tracheotomy on duration of mechanical ventilation. IV = inverse variance.

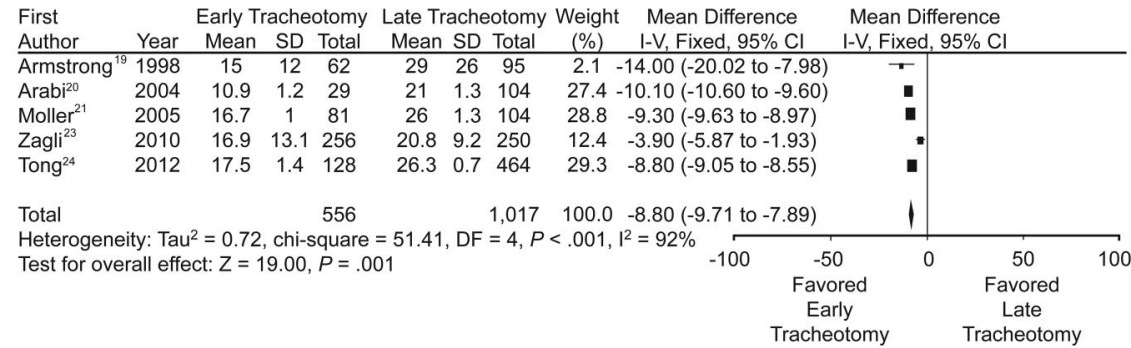

Fig. 3. Meta-analysis of 5 randomized controlled trials on the impact of early versus late tracheotomy on ICU stay. IV $=$ inverse variance.

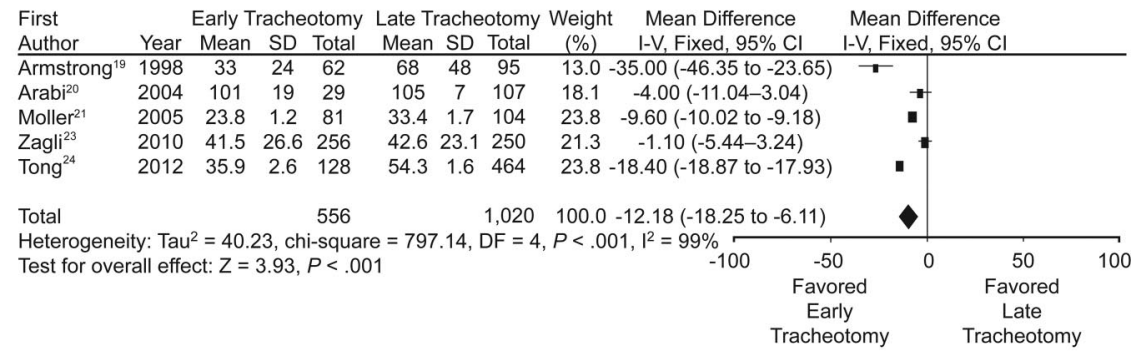

Fig. 4. Meta-analysis of 5 randomized controlled trials on the impact of early versus late tracheotomy on hospital stay. IV $=$ inverse variance.

The funnel plot showed no publication bias for studies included in the meta-analysis in terms of mortality. We also calculated the $\mathrm{N}_{\mathrm{fs} 0.05}$ for each end point event, and found that the $\mathrm{N}_{\mathrm{fs} 0.05}$ values for ICU stay, hospital stay, mechanical ventilation duration, VAP, and mortality were greater than the number of studies included in the meta-analysis. 


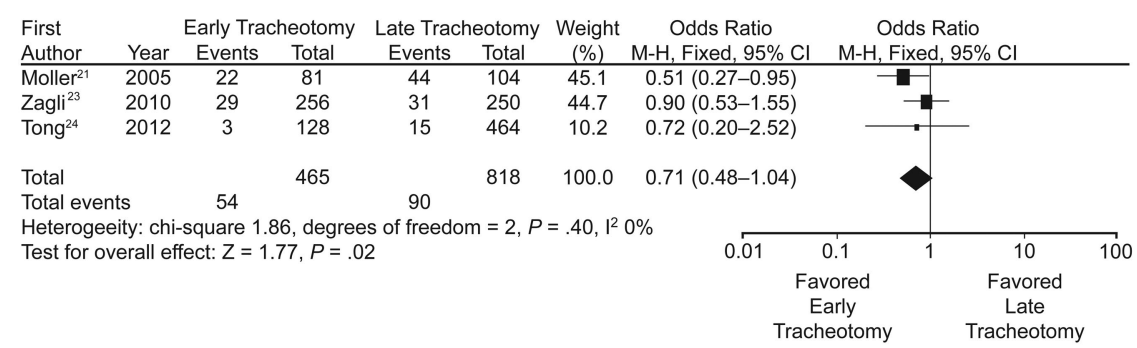

Fig. 5. Meta-analysis of 3 randomized controlled trials on the impact of early versus late tracheotomy on ventilator-associated pneumonia. $\mathrm{M}-\mathrm{H}=$ Mantel-Haenszel test.

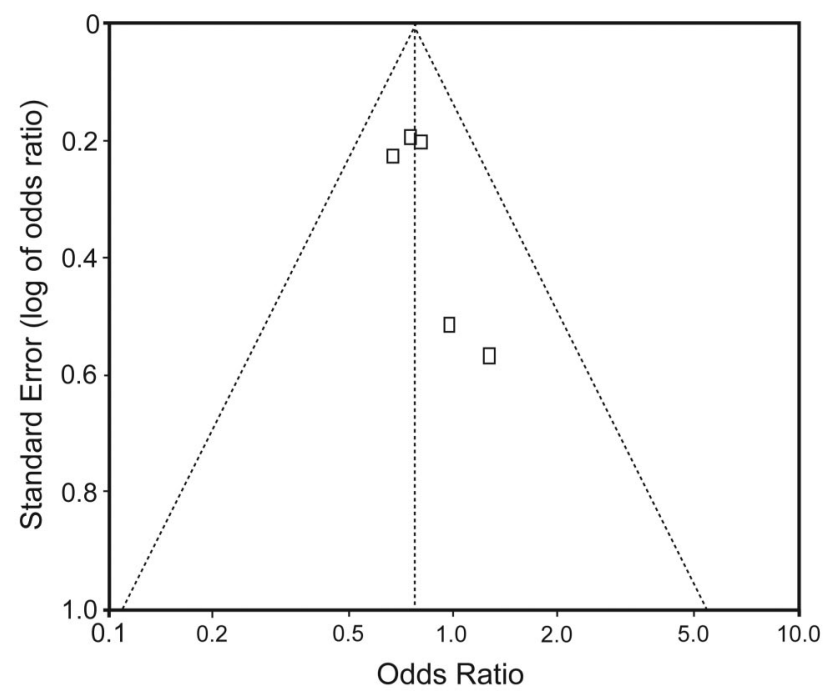

Fig. 6. Funnel plot of the likelihood of publication bias regarding mortality in the analyzed studies.

\section{Discussion}

This was the first meta-analysis that pooled data from observational studies to assess the impact of tracheotomy timing on clinical outcomes of critically ill patients. The great discovery of this updating review was that patients who underwent early tracheotomy had a $12 \%$ lower mortality rate than those who underwent late tracheotomy. Conversely, previously published reviews ${ }^{10-12}$ did not find any survival benefit with respect to early tracheotomy. Earlier reviews were all based on RCTs. Other retrospective analyses drew the same conclusions. In the study conducted by Freeman et al, which included 43,916 critically ill patients, patients undergoing tracheotomy had a lower mortality rate than non-tracheotomy patients. ${ }^{2}$ Scales and colleagues compared early $(\leq 10 \mathrm{~d})$ and late $(>10 \mathrm{~d})$ tracheotomies in another retrospective study, involving 10,927 patients, and found significant reductions for unadjusted 90-day, 1-year mortality, and study mortality in the early tracheotomy groups. ${ }^{18}$
One might ask why well designed, prospective trials were unable to identify an effect on survival outcome. First, it was difficult to distinguish the population of interest who really required prolonged intubation or mechanical ventilation, and the inclusion criteria were quite variable. In RCT research it is possible that some low-risk patients who did not really need a tracheotomy eventually underwent the procedure, and the potential benefit of early tracheotomy may have been diluted. ${ }^{25}$ Second, in the observational studies, judgment of tracheotomy performance depended on the clinical team's discussions and individual opinions. Conversely, the selection of tracheotomy in retrospective studies reflected the real clinical status, and perhaps critically ill patients in observational studies really needed the procedure when it was performed. Third, RCTs generally had small samples, due to difficulties associated with implementing this type of study, whereas observational studies had larger samples, and in the present analysis a total of 2,037 subjects were analyzed.

The present meta-analysis also found other advantages, such as decreased mechanical ventilation duration, ICU stay, and hospital stay, which is in accordance with conclusions from other meta-analyses. ${ }^{10-12}$ Freeman et al determined that tracheotomy timing correlated significantly with mechanical ventilation duration, ICU stay, and hospital stay, in a study where tracheotomy timing was considered as a consecutive parameter. ${ }^{2}$ Therefore, the advantages of resources and time savings should be interpreted as a consensus. We found that early tracheotomy can shorten mechanical ventilation by about 10 days, which greatly reduces the need for nursing care and medical expenditures. The average cost of ICU patients requiring mechanical ventilation was $\$ 3,968$ per day, according to research conducted by Dasta et al. ${ }^{26}$ Therefore, the overall cost saving of early tracheotomy, compared with late tracheotomy, could reach $\$ 40,000$, based on our finding of 10 days reduction of mechanical ventilation time. Reduction of ICU stay and hospital stay would also mean saving of ICU cost and medical resources.

With regard to VAP, neither our research based on observational studies nor meta-analyses based on RCTs found evidence that early tracheotomy can influence the rate of 


\section{Benefits of Early Tracheotomy: A Meta-analysis}

VAP. Other studies also failed to demonstrate timing of tracheotomy in relation to VAP. ${ }^{27,28}$ However, we did observe a trend toward reduced VAP when tracheotomy was performed between days 3 and 7 (odds ratio $0.71, P=.08$ ). Whether even earlier tracheotomy (before day 3) would have additional benefits remained unclear. In a study conducted by Rodriguez et al, patients who underwent tracheotomy within the first 48 hours had significantly decreased likelihoods of developing VAP. ${ }^{29}$ It was difficult to interpret the controversial results of numerous studies because of varying definitions of VAP. Several factors may explain the possible mechanisms of the negative results. Performing a tracheotomy destroys the natural structure of the airway, which affects its ability to protect the respiratory system. For example, the cough reflex is greatly attenuated because the glottis is inactive. ${ }^{30}$ In the ICU setting, frequent invasive handling or air contaminated with pathogenic microorganisms may counteract the benefits of tracheotomy, such as pulmonary toilet or convenient nursing care.

This study has several limitations. The definition of mortality differed among studies, varying from ICU to 1 -year mortality. The detailed VAP diagnostic criteria were not mentioned in all of the studies analyzed, and it was unclear whether VAP was diagnosed before or after tracheotomy. ${ }^{21,23,24}$ With regard to mechanical ventilation duration, the lack of a uniform weaning protocol also confused the interpretation of the data. Finally, because the database was not suitable, post-hospitalization events and resource expenditures could not be specifically examined.

\section{Conclusions}

Although the conclusions drawn from observational studies were less convincing in comparing RCTs in evidencebased medicine, the benefits of early tracheotomy were obvious, and critical care physicians should carefully consider them when encountering the optimal timing of tracheotomy. Based on our findings, we recommend that tracheotomy be performed between days 3 and 7 , once the decision had been made.

\section{ACKNOWLEDGMENTS}

We thank Xiubo Jiang, School of Public Health, Qingdao University, Qingdao, China, for assistance with statistical methods.

\section{REFERENCES}

1. Durbin CG Jr. Tracheostomy: why, when, and how. Respir Care 2010;55(8):1056-1068.

2. Freeman BD, Borecki IB, Coopersmith CM, Buchman TG. Relation- ship between tracheostomy timing and duration of mechanical ventilation in critically ill patients. Crit Care Med 2005;33(11):2513-2520.

3. De Leyn P, Bedert L, Delcroix M, Depuydt P, Lauwers G, Sokolov $\mathrm{Y}$, et al. Tracheotomy: clinical review and guidelines. Eur J Cardiothorac Surg 2007;32(3):412-421.

4. Cox CE, Carson SS, Holmes GM, Howard A, Carey TS. Increase in tracheostomy for prolonged mechanical ventilation in North Carolina, 1993-2002. Crit Care Med 2004;32(11):2219-2226.

5. Nieszkowska A, Combes A, Luyt CE, Ksibi H, Trouillet JL, Gibert C, Chastre J. Impact of tracheotomy on sedative administration, sedation level, and comfort of mechanically ventilated intensive care unit patients. Crit Care Med 2005;33(11):2527-2533.

6. Diehl JL, El AS, Touchard D, Lemaire F, Brochard L. Changes in the work of breathing induced by tracheotomy in ventilator-dependent patients. Am J Respir Crit Care Med 1999;159(2):383-388.

7. King C, Moores LK. Controversies in mechanical ventilation: when should a tracheotomy be placed. Clin Chest Med 2008;29(2):253263.

8. Shah RK, Lander L, Berry JG, Nussenbaum B, Merati A, Roberson DW. Tracheotomy outcomes and complications: a national perspective. Laryngoscope 2012;122(1):25-29.

9. Plummer AL, Gracey DR. Consensus conference on artificial airways in patients receiving mechanical ventilation. Chest 1989;96(1): 178-180.

10. Griffiths J, Barber VS, Morgan L, Young JD. Systematic review and meta-analysis of studies of the timing of tracheostomy in adult patients undergoing artificial ventilation. BMJ 2005;330(7502): 1243.

11. Dunham CM, Ransom KJ. Assessment of early tracheostomy in trauma patients: a systematic review and meta-analysis. Am Surg 2006;72(3):276-281.

12. Wang F, Wu Y, Bo L, Lou J, Zhu J, Chen F, et al. The timing of tracheotomy in critically ill patients undergoing mechanical ventilation: a systematic review and meta-analysis of randomized controlled trials. Chest 2011;140(6):1456-1465.

13. Terragni PP, Antonelli M, Fumagalli R, Faggiano C, Berardino M, Pallavicini FB, et al. Early vs late tracheotomy for prevention of pneumonia in mechanically ventilated adult ICU patients: a randomized controlled trial. JAMA 2010;303(15):1483-1489.

14. Hsu CL, Chen KY, Chang CH, Jerng JS, Yu CJ, Yang PC. Timing of tracheostomy as a determinant of weaning success in critically ill patients: a retrospective study. Crit Care 2005;9(1):R46-R52.

15. Combes A, Luyt CE, Nieszkowska A, Trouillet JL, Gibert C, Chastre J. Is tracheostomy associated with better outcomes for patients requiring long-term mechanical ventilation. Crit Care Med 2007;35(3): 802-807.

16. Clec'h C, Alberti C, Vincent F, Garrouste-Orgeas M, de Lassence A, Toledano D, et al. Tracheostomy does not improve the outcome of patients requiring prolonged mechanical ventilation: a propensity analysis. Crit Care Med 2007;35(1):132-138.

17. Arabi YM, Alhashemi JA, Tamim HM, Esteban A, Haddad SH, Dawood A, et al. The impact of time to tracheostomy on mechanical ventilation duration, length of stay, and mortality in intensive care unit patients. J Crit Care 2009;24(3):435-440.

18. Scales DC, Thiruchelvam D, Kiss A, Redelmeier DA. The effect of tracheostomy timing during critical illness on long-term survival. Crit Care Med 2008;36(9):2547-2557.

19. Armstrong PA, McCarthy MC, Peoples JB. Reduced use of resources by early tracheostomy in ventilator-dependent patients with blunt trauma. Surgery 1998;124(4):763-766; discussion 766-767.

20. Arabi Y, Haddad S, Shirawi N, Al SA. Early tracheostomy in intensive care trauma patients improves resource utilization: a cohort study and literature review. Crit Care 2004;8(5):R347-R352. 


\section{Benefits of Early Tracheotomy: A Meta-analysis}

21. Moller MG, Slaikeu JD, Bonelli P, Davis AT, Hoogeboom JE, Bonnell BW. Early tracheostomy versus late tracheostomy in the surgical intensive care unit. Am J Surg 2005;189(3):293-296.

22. Flaatten H, Gjerde S, Heimdal JH, Aardal S. The effect of tracheostomy on outcome in intensive care unit patients. Acta Anaesthesiol Scand 2006;50(1):92-98.

23. Zagli G, Linden M, Spina R, Bonizzoli M, Cianchi G, Anichini V, et al. Early tracheostomy in intensive care unit: a retrospective study of 506 cases of video-guided Ciaglia Blue Rhino tracheostomies. J Trauma 2010;68(2):367-372.

24. Tong CC, Kleinberger AJ, Paolino J, Altman KW. Tracheotomy timing and outcomes in the critically ill. Otolaryngol Head Neck Surg 2012;147(1):44-51.

25. Veelo DP, Gajic O, Schultz MJ. Benefits of early tracheotomy: underpowered or overestimated. Intensive Care Med 2008;34(12): 2309; author reply 2310-2311.
26. Dasta JF, McLaughlin TP, Mody SH, Piech CT. Daily cost of an intensive care unit day: the contribution of mechanical ventilation. Crit Care Med 2005;33(6):1266-1271

27. Carrilho CM, Grion CM, Bonametti AM, Medeiros EA, Matsuo T. Multivariate analysis of the factors associated with the risk of pneumonia in intensive care units. Braz J Infect Dis 2007;11(3): 339-344.

28. Apostolopoulou E, Bakakos P, Katostaras T, Gregorakos L. Incidence and risk factors for ventilator-associated pneumonia in 4 multidisciplinary intensive care units in Athens, Greece Respir Care 2003;48(7):681-688.

29. Rodriguez JL, Steinberg SM, Luchetti FA, Gibbons KJ, Taheri PA, Flint LM. Early tracheostomy for primary airway management in the surgical critical care setting. Surgery 1990;108(4):655-659.

30. Boitano LJ. Management of airway clearance in neuromuscular disease. Respir Care 2006;51(8):913-922; discussion 922-924.

This article is approved for Continuing Respiratory Care Education credit. For information and to obtain your CRCE

(free to AARC members) visit

www.rcjournal.com 